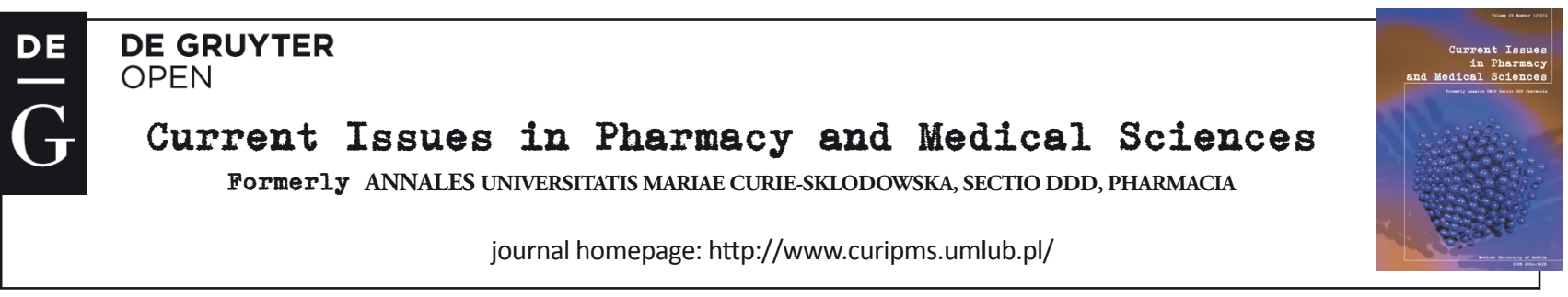

\title{
Hypertension in pediatric dentistry practice
}

Joanna Rosiak, Beata Kubic-Filiks, Jolanta Szymanska*

Chair and Department of Paedodontics, Medical University of Lublin, Karmelicka 7, 20-081 Lublin, Poland

\begin{tabular}{|c|c|}
\hline ARTICLE INFO & ABSTRACT \\
\hline $\begin{array}{l}\text { Received } 05 \text { May } 2016 \\
\text { Accepted } 15 \text { July } 2016\end{array}$ & \multirow{2}{*}{$\begin{array}{l}\text { The authors discuss the factors coexistent with hypertension both in children and youth, } \\
\text { as well as the treatment methods and possible symptoms that might appear in the oral } \\
\text { cavity. In the work, the authors emphasize that there is a need for cooperation between } \\
\text { the general practitioner, a cardiologist and a dentist, so as to provide an early diagnosis } \\
\text { and effective treatment, as well as to prevent complications with regard to hypertension } \\
\text { itself and the drugs used in treatment. The discussion is based on a review of the most } \\
\text { recent works in the field. }\end{array}$} \\
\hline $\begin{array}{l}\text { Keywords: } \\
\text { hypertension, } \\
\text { children and youth, } \\
\text { dentist. }\end{array}$ & \\
\hline
\end{tabular}

\section{INTRODUCTION}

Hypertension, as reported in children and youths, can be either primary (also called essential), as well as idiopathic. Of note, it can be triggered by some other diseases [16]. In infants and little children, hypertension can be induced by primary kidney diseases, heart defects, coarctation of the aorta or endocrine disorders. With regard to older children, the trigger is nephropathy or nephritis, while, with youths, idiopathic hypertension can come about via interstitial kidney diseases $[18,20,22]$.

The cause of essential hypertension in children is largely unknown, although there is a body of literature suggesting a relationship with pre-existing diabetes or high cholesterol levels, with obesity and with being a part of a certain ethnic group or with some genetic predispositions [4,6,12,21,23].

According to the most recent guidelines, pre-hypertension in children is indicated via the exhibition of high blood pressure. Hypertension itself is categorized as either hypertension I and II [16]. Diagnosing hypertension in children is extremely challenging, since defining what is a correct blood pressure depends on a whole variety of factors, among these, the child's age, sex or height [25]. There has been some clinical research measuring blood pressure in children using the ausculatory method. Herein, the blood pressure percentiles are dependent on the age and gender group, with seven height categories in mind $[12,16]$. Currently, it is estimated that in a healthy child, both the systolic and diastolic pressure should be lower than 90 percentiles. Children are diagnosed with hypertension when three consecutive measurements show readings equal to or higher than 95 percentiles, while values between 90 and 95 percentiles are considered to be pre-hypertension $[12,25]$.

\footnotetext{
* Corresponding author

e-mail: szymanska.lublin@gmail.com
}

There is a tendency to consider adult hypertension being pre-existing in childhood. Indeed, various research has demonstrated that individuals reporting high blood pressure in their childhood years are more likely to develop hypertension later in life [12].

Successful therapeutic methods include both pharmacological and non-pharmacological treatment. The latter pertains to changing one's lifestyle - increasing physical activity, switching one's diet, mainly by curbing intake of salt, monosacharides or saturated fats, as well as including vegetables, fruits and multigrain products in the diet. In the case of certain adult patients, this also includes quitting smoking and limiting alcohol consumption $[5,13,18,23,27,28]$.

\section{FACTORS COEXISTING WITH HYPERTENSION}

The awareness of the risk factors that may lead to hypertension in children plays a key role both in recognizing and treating hypertension. For instance, there is a clear link between obesity and hypertension [4]. Cintez et al., for example, conducted a study looking at children and youths aged 3-17, all living in the Bucharest region. Their study reveals that some $7.4 \%$ of the population suffers from hypertension. The very same study puts forward that the male population is more likely to report hypertension, and that it is related with factors such as being overweight or obese (which mostly pertains to abdominal obesity) [2]. Puri et al. conducted a similar study in the area of New York City, looking at individuals aged 6 to 19. Herein, they state that some $31 \%$ of all obese subjects reported higher blood pressure, while only $3 \%$ of those with normal weight had the same [12]. In conjunction with the aforementioned, Reich et al. note that children who have high body mass 
index (BMI) readings are more likely to be suffering from hypertension. This study was conducted on German children of all age groups (8-9 years, 11-12 years, and 15-16 years). An additional outcome of this work was the recognition of a relationship between fat percentage and hypertension in children aged 11-12 and 15-16 [19]. Dulskiene et al., in their work, looked at Lithuanian teenagers aged 12-15, and they saw that both hypertension and increased blood pressure are closely related to excessive weight, obesity and abdominal obesity [6]. Costa et al. in their research looking at Brazilian youth (12-18 years), have also shown there is a direct relationship both between heightened BMI and excessive waist circumference and the risk of hypertension development in both sexes. They noted that being overweight or obese in this group is accompanied by increased blood pressure, and can lead to certain glucose and fat metabolism abnormalities [3]. Beyond the aforementioned studies, Martion et al. have discerned some significantly higher values of BMI and waist-hip ratio (WHR) in hypertensive children and youth, when compared against those with correct blood pressure. Furthermore, they also noticed increased insulin levels in patients suffering from hypertension. In addition, most patients suffering from hypertension have reported hypertension in one of the parents [14].

Excessive weight and obesity are one of the main factors affecting the development of hypertension and the increase in its prevalence among children and youths. Related to this, researchers have found a link between salt intake and increased hypertension in children [7]. He et al. have demonstrated that there is a relationship between the decreased of salt intake and the lowering of blood pressure in children [10]. With respect to this issue, Kuciene et al. researched a population of children, aged 12-15, all residents of the Kaunas area (Lithuania). In this study, they found a statistically significant relationship between short sleep time (which means less than 8 hours a day) and the risk of hypertension and increased blood pressure [11]. Hence, monitoring the sleep quality in children might provide important clues as to recognizing and treating hypertension. Interestingly, further research has shown that some $15 \%$ of children reporting hypertension tend to snore, while the other 1-3\% suffer from other sleep distortions [18].

With regard to the issue of pregnancy and hypertension, Fraser et al. have found a link between preeclampsia in pregnant women or gestational hypertension and increased blood pressure in their children (this pertains to both systolic and diastolic pressure) [8]. In addition, Vohr et al. in their research looking at teenagers of the Caucasian race have noted that young people who were born prematurely are more likely to suffer from hypertension. Other research shows there is a link between increased blood pressure in children that were born prematurely and lowered birth weight [26]. What is more, head trauma sustained during the infant period is now known to be related to increased values of diastolic pressure. Furthermore, some reports see ECG changes in children and youth suffering from hypertension. Thus, problems with neuromuscular conductivity can lead to cardiomyopathy $[1,9]$.

\section{HYPERTENSION TREATMENT}

Blood pressure treatment should be accompanied with lifestyle changes. The recommendations include, among others, regular exercising which can lower blood pressure. Individuals suffering from obesity or excessive weight should also consider dietary changes, like curbing down on saturated fats, salt and monosaccharide, as well as including vegetables, fruits and multigrain products in their diet [5, $13,17,18,27,28]$.

Pharmacological treatment of hypertension in children sparks controversy, since the long-term effects of using hypertension medicines are yet to be known - indeed, they may adversely affect the development of the child. The recommendations for starting pharmacological treatment in children include: secondary hypertension, heart problems, chronic kidney diseases, diabetes or failed non-pharmacological treatment used as a means of lowering blood pressure $[12,18]$. The groups of drugs used for treating hypertension in children include: angiotensin-converting enzyme (ACE) inhibitors, angiotensin II receptor antagonists, calcium channel blockers, diuretics, $\beta$-blockers $[15,18]$.

ACE inhibitors, calcium channel blockers, angiotensin II receptor antagonists should be drugs of the first choice for treating hypertension in children, since they have been proven to be effective and safe for children, as the child's body tolerates them well. ACE inhibitors drugs are most usually chosen by doctors since these can be applied in a single dose and also they have little side effects [15].

What should be underlined is that before the hypertension treatment is commenced, there is a need for good recognition and treatment of the underlying disease. In the case of secondary hypertension, it is ACE inhibitors and angiotensin II receptor antagonists that should be used for treatment. The latter antagonists are hugely effective for both lowering blood pressure and reducing proteinuria [15].

Still, most patients affected by hypertension should be treated using a combination therapy, as doing so makes it easier to avoid undesired actions or to find their cause [5, $13,27]$.

\section{WHEN A CHILD WITH HYPERTENSION VISITS A DENTIST}

Children suffering from hypertension should be diagnosed as early as possible, since there is a risk of complications caused by the heart system. In this respect, dentists have an important role in the screening of undiagnosed and under-treated hypertension, as they are often the first medical practitioner to encounter a child. This, in turn, may lead to improved monitoring and treatment.

In 1976, the American Dental Association issued a recommendation about measuring blood pressure, both in children and adults. This was implemented in 2004, as it took many years to complete the correct blood pressure charts for children and youths. The recommendations used now require dentists to measure the blood pressure in every child older than 3 , during every visit to the dentist, no matter what its purpose is. In light of that, there is a need to educate the staff 
of the dental surgery about the proper ways of measuring blood pressure in children [25].

Researchers suggest that monitoring the blood pressure can improve the hypertension detection rates in children $[10,18,25]$. In assessing general fitness, and particularly hypertension risk, the dentist should learn about the child's medical history, particularly looking at blood pressure in the family. He or she should, as well, focus on eliciting information about the drugs that child takes or their diet. Such information might help the pediatric specialist ascertain potential problems with blood pressure in that child. Furthermore, dentists should also measure the child's blood pressure prior to any treatment, as well as during the treatment or after it is finished. During the measuring, any risk factors that can increase the blood pressure reading should be avoided. In case of children of the risk group, it is important to monitor the pressure all the time so as to avoid the consequences of "white coat hypertension". Indeed, it is now considered unacceptable not to monitor the pressure in children of the risk group.

It should be emphasized that in case of younger patients, in particular those who have been diagnosed with hypertension, especially untreated or poorly treated, local anesthetics containing vasoconstrictors should not be used [18].

It should also be remembered that there might be some interactions between the drugs used for treating hypertension in children, especially those containing ACE inhibitors, ß-blockers or diuretics, and non-steroid anti-inflammatory medicines. Thus, non-steroid medicine should be applied to children for a maximum of 10 days only $[18,20]$.

There is only a small body of literature devoted to the side effects of hypertension treatment in children. What these state is that unintended treatment effects are especially visible on the skin and around the mucous membrane in the oral cavity. Moreover, in children treated for hypertension, there is a higher incidence of telangiectasia (around the skin of the cheeks) and gingival hyperplasia, when patients ceased to take amlodypine (a calcium channel blocker) [24]. What is more, some reports note enlargement of the tongue and Quincke edema as reactions to nicradipine and amlodypine treatment [17]. Calcium channel blockers may also cause kserostomy to appear. This can lead to an increase in the intensity of the caries disease, oral mucosa ulcerations, taste disorders or gum diseases [18]. Due to the possible side effects held by the drugs used for treating hypertension in children, it is extremely important to provide regular periodontological control to this group of patients $[17,18,24]$.

\section{CONCLUSION}

Due to the lifestyle changes among children and youth, especially the avoidance of physical activity and the held bad dietary habits (following diets rich in saturated fats, simple carbohydrates or salt), various health problems can appear. Overweight and obesity has become much more common today, and this leads to the development of hypertension. Initially, the experienced hypertension is asymptomatic, yet in the later period, some internal signs and symptoms organs start to appear. Therefore, it is important to quickly diagnose and treat childhood hypertension. Dentists play a key role in this respect, since they have a chance to check children's health much more commonly than do the majority of medical pediatricians.

Changes in the oral cavity in children and young people suffering from hypertension come about by both the disease itself, as well as the pharmacological items used for treating. Plus to that, combination therapy makes it much harder to find the cause for the changes in the oral cavity. Patients with hypertension, along with the underlying diseases are, like everyone else, subjected to dental care, both in terms of prophylaxis and treatment. Effective and timely treatment for hypertension would let decrease or even eliminate the problematic complications and prevent the changes in the oral cavity that result from the pharmacotherapy used to treat hypertension.

\section{REFERENCES}

1. Chavez E. et al: P-Wave Dispersion: a possible warning sign of hypertension in children. MEDICC Review, 16, 31, 2014.

2. Cintez E. et al.: Hypertension in Romanian children and adolescents: a cross-sectional survey. Maedica J. Ciln. Med., 8, 5, 2013.

3. Costa J.V. et al.: An analysis of risk factor for arterial hypertension in adolescent students. Latino-Am. Enfermagem, 20, 289, 2012.

4. Denney-Wilson E. et al.: Body mass index, waist circumference, and chronic disease risk factors in Australian adolescents. Arch. Pediatr. Adolesc. Med., 162, 566, 2008.

5. Dickinson H.O. et al.: Lifestyle interventions to reduce raised blood pressure: a systematic review of randomized controlled trials. J. Hypertens., 24, 215, 2006.

6. Dulskiene V. et al.: Association between obesity and high blood pressure among Lithuanian adolescents:a cross-sectional study. Ital. J. Pediatr., 40, 102, 2014.

7. Falkner B.: Recent clinical and translational advances in pediatric hypertension. Hypertension, 65, 926, 2015

8. Fraser A. et al.: Hypertensive disorders of pregnancy and cardiometabolic health in adolescent offspring. Hypertension, 62, 614, 2013.

9. Grosu V.: The research of parameters of cardiac rhythm variability of arterial hypertension in children and adolescents. Practica Medicala, 9, 264, 2014.

10. He F.J., MacGregor G.A.: Importance of salt in determining blood pressure in children: meta-analysis of controlled trials. Hypertension, 48, 861, 2006.

11. Kuciene R., Dulskiene V.: Associations of short sleep duration with prehypertension and hypertension among Lithuanian children and adolescents: a cross-sectional study. BMC Public Health, 14, 255, 2014.

12. Lubre E.: Nadciśnienie tętnicze u dzieci i młodzieży. Choroby Serca i Naczyń, 7, 107, 2010.

13. Mancia G. et al.: Wytyczne ESH/ESC dotyczące postępowania w nadciśnieniu tętniczym w 2013 roku. Kardiol. Pol., 7, 27, 2013.

14. Martion F. et al.: Hypertension in children and adolescents attending a lipid clinic. Eur. J. Pediatr., 172, 1573, 2013.

15. Meyers R.S., Siu A.: Pharmacotherapy review of chronic pediatric hypertension. Clin. Ther., 11, 1331, 2011.

16. National High Blood Pressure Education Program Working Group on High Blood Pressure in Children and Adolescents. The Fourth Report on the diagnosis, evaluation, and treatment of high blood pressure in children and adolescents. Pediatrics, 114 (suppl), 555, 2004.

17. Pierce W.A. et al.: Angioedema associated with dihydropyridine calcium-channel blockers in a child with Burkitt lymphoma. Am. J. Health Syst. Pharm., 68, 402, 2011.

18. Pinto A., Ronal R., Sollecito T.P.: Hypertension in children: an overview. J. Dent. Educ., 70, 434, 2006.

19. Reich A et al.: Obesity and blood pressure: results from the examination of 2365 school children in Germany. Int. J. Obes. Relat. Metab. Disord., 27, 1459, 2003. 
20. Seeman T. et al.: Ambulatory blood pressure correlates with renal volume and number of renal cysts in children with autosomal dominant polycystic kidney disease. Blood Press Monit., 8, 107, 2003.

21. Song S.H.: Early-onset type 2 diabetes mellitus: A condition with elevated cardiovascular risk? Br. J. Diabetes Vasc. Dis., 8, 61, 2008.

22. Sorof J.M. et al.: Cardiovascular risk factors and sequelae in hypertensive children identified by referral versus school-based screening. Hypertension, 43, 214, 2004.

23. Torrance B. et al.: Overweight, physical activity and high blood pressure in children: a review of the literature. Vasc. Health Risk Manag., 3, 139, 2007.

24. Van der Vleuten C.J., Trijbels-Smeulders M.A., van de Kerkhof P.C. Telangiectasia and gingival hyperplasia as side-effects of amlodipine (Norvasc) in a 3-year-old girl. Acta Derm. Venereol., 79, 323, 1999.
25. Viswanathan K. et al.: Monitoring pediatric blood pressure at dental appointments. J. Dent. Child., 77, 140, 2010.

26. Vohr B.R. et al.: Early predictors of hypertension in prematurely born adolescents. Acta Paediatr., 99, 1812, 2010.

27. Wełnicki M., Mamcarz A., editors (2014). Nadciśnienie tętnicze. Jak leczyć skuteczniej? Warszawa: Medical Education Sp. z o. o.,

28. Williams C.L. et al.: Cardiovascular health in childhood: a statement for health professionals from the Committee on Atherosclerosis, Hypertension, and Obesity in the Young (AHOY) of the Council on Cardiovascular Disease in the Young, American Heart Association. Circulation, 106, 143, 2002. 